\title{
EFFECTS OF FATIGUE ON THE INTEGRITY OFA FRCITION STIR WELDED LAP JOINT CONTAINING RESIDUAL STRESSES
}

\author{
Michael Bach ${ }^{1(*)}$, Ali Merati ${ }^{2}$, Michael Gharghouri ${ }^{3}$ \\ ${ }^{1}$ Department of Mechanical Engineering, Carleton University, Ottawa, Canada \\ ${ }^{2}$ National Research Council, Ottawa, Canada \\ ${ }^{3}$ National Beam Center, Chalk Rivers, Canada \\ ${ }^{(*}$ Email: utopia5000@hotmail.com
}

Keywords: residual stress, fatigue life, friction stir welding, neutron diffraction, and crack nucleation

\begin{abstract}
This research uses a non-destructive method of neutron diffraction to measure the tri-axial residual stresses in a friction stir welded aerospace fuselage component: a stringer-to-skin lap joint. Two different specimens were examined. Fatigue testing was performed on both specimens to determine their fatigue lives. Effects of the different components of residual stresses were examines and related to fatigue performance. A combination of fractography, hardness testing, and residual stress measurement was used to predict areas of high probability of structural failure in the friction stir welded lap joints.
\end{abstract}

\section{Introduction}

Most monocoque aircraft fuselages design consists of several key components. The circular frames give the fuselage its cylindrical shape and are spaced evenly in the longitudinal direction of the aircraft. Surrounding the frames are the stringers, which help increase structural integrity of the fuselage and help against bending and torsional loads. The entire aircraft is covers in thin aluminum skin panels. These frames, stringers and skin are typically fabricated from 2XXX and 7XXX series aluminum alloys for their high strength-to-weight ratios.

In recent years, there has been a demand to come up with better joining alternatives for these aluminum structures that faster, stronger and more economical to produce. One such joining method is call friction stir welding. Friction stir welding is a solid-state process, which used frictional heat to blend the two joining materials together and create a metallurgical bond. Studies had concluded that friction welding has an improved static strength to that of a single row of rivets with the same dimensions [1].

One problem associated with friction welding is the residual stresses that are left in the components once the welding is cooled and the component is removed from the clamps. Although the heat input in friction welding is lower than that of fusion welding, residual stressed continue to plague friction welding process. An example of the effects of distortion in FSW is shown in Figure 2. The image on the left is that of an as-welded FSW AA 7075-T6 stringer to an AA 2024-T3 skin panel. There is a clear distortion in the $3.76 \mathrm{~mm}$ thick plate. The plate on the right has undergone a post-welding surface treatment process known as hammer peening which caused the distortion to be dramatically reduced [2]. Hammer peening involved plastically straining a material using a hand held peening tool with an oscillating tip, which produces small, round indentations on the surface.

The purpose of this paper is to examine the effects of fatigue on the integrity of the friction stir welded lap joint containing residual stresses. The first part of the paper will examine measuring the residual stresses using a non-destructive residual stress technique known as neutron diffraction. The 
second part of the paper will then examine the effects of these residual stresses combined with other metallurgical characteristics to determine their effects on the fatigue lives of the lap joints both before and after hammer peening.

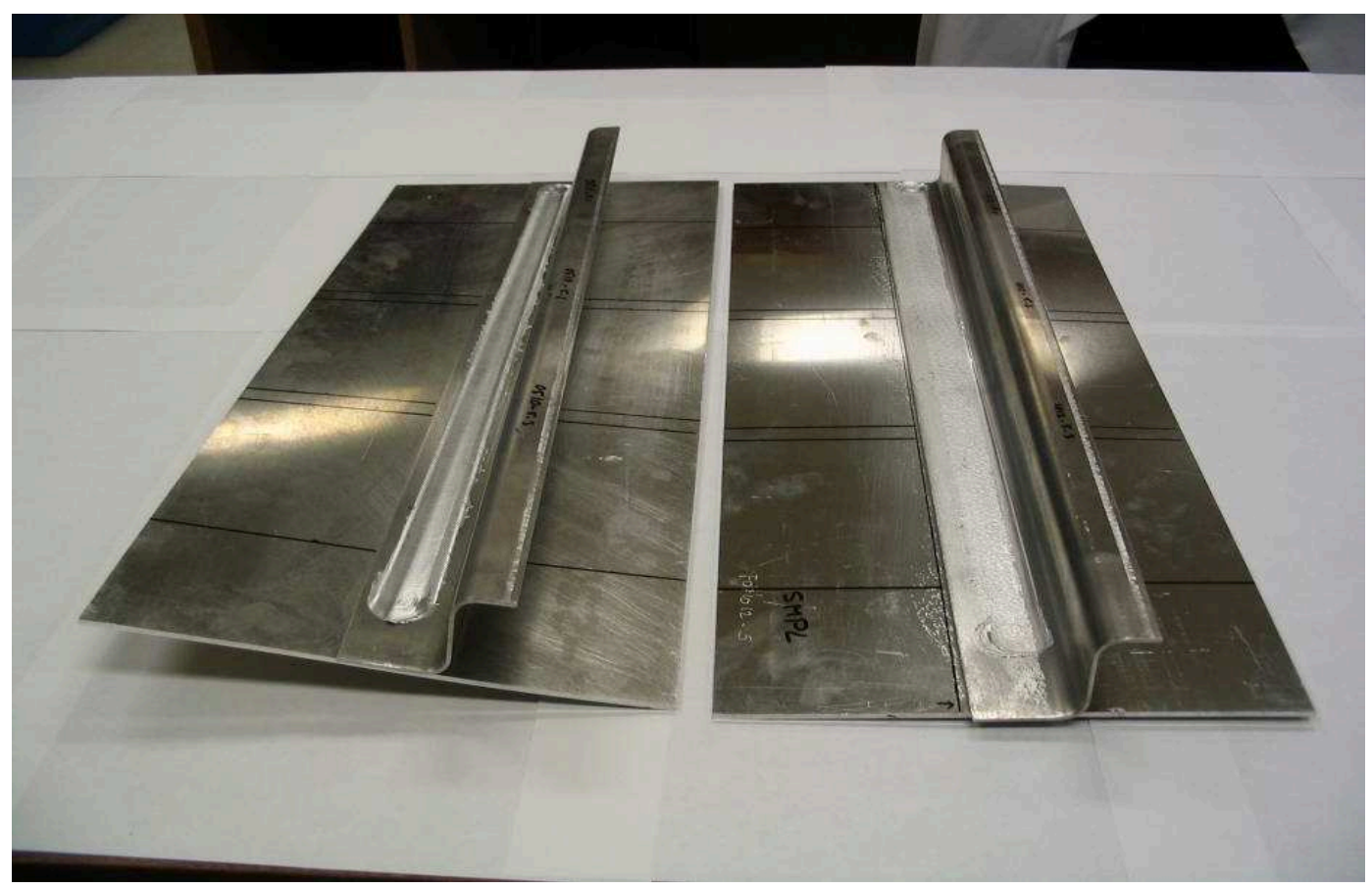

Figure 1: FSW plate before and after hammer peening [2]

\section{Experimental Procedure}

Neutron diffraction was chosen as a non-destructive method of determining the internal distribution of strains by means of intersecting incident and diffracted neutron beams to form a small sampling volume that was fixed in space. The corresponding residual stresses were then calculated in the three principal directions and compared with the results of the compliance method.

All neutron diffraction experiments were carried out at the National Research Council's Canadian Neutron Beam Centre in Chalk River on an L3 spectrometer. Two test specimens were used in the experiments. The first specimen was an as-welded plate measuring $191 \times 95 \times 3.76 \mathrm{~mm}$, and the second specimen was the hammer peened plate with identical dimensions. The peening was carried out on the top surface of the plate and in the weld region only. Figure 2 is a close-up view of the experimental setup, which shows the scattering and diffraction beam slits. Strain measurements for both test specimens were taken at the mid section of the plates in the $x-y$ plane. The weld centerline was taken to be zero position, five points were chosen to the right side of the weld centerline, towards the stringer and eight points were chosen to the left of the weld centerline. Since the gauge volume produced by the intersection of the incident and scattering beam was $0.5 \mathrm{~mm}$, strains were measured at six depths of $y=0.325,0.97,1.625,2.275,2.925$, and $3.575 \mathrm{~mm}$ from the top surface. Using a slit with a neutron-absorbing cadmium mask, the dimensions of the match-like gauge volume were defined to be $0.5 \mathrm{~mm} \times 0.5 \mathrm{~mm} \times 20 \mathrm{~mm}$ with the long axis pointing in the z-direction. An Si monochromatic neutron beam with wavelength, $\lambda=1.72 \mathrm{~A}$, and diffraction from $\{311\}$ lattice planes were used for the analysis as it is most representative of the elastic response of the bulk material (AA 2024-T3). According to Bragg's law, the corresponding scattering angle (2 $\theta)$ was determined to be $83^{\circ}$. 


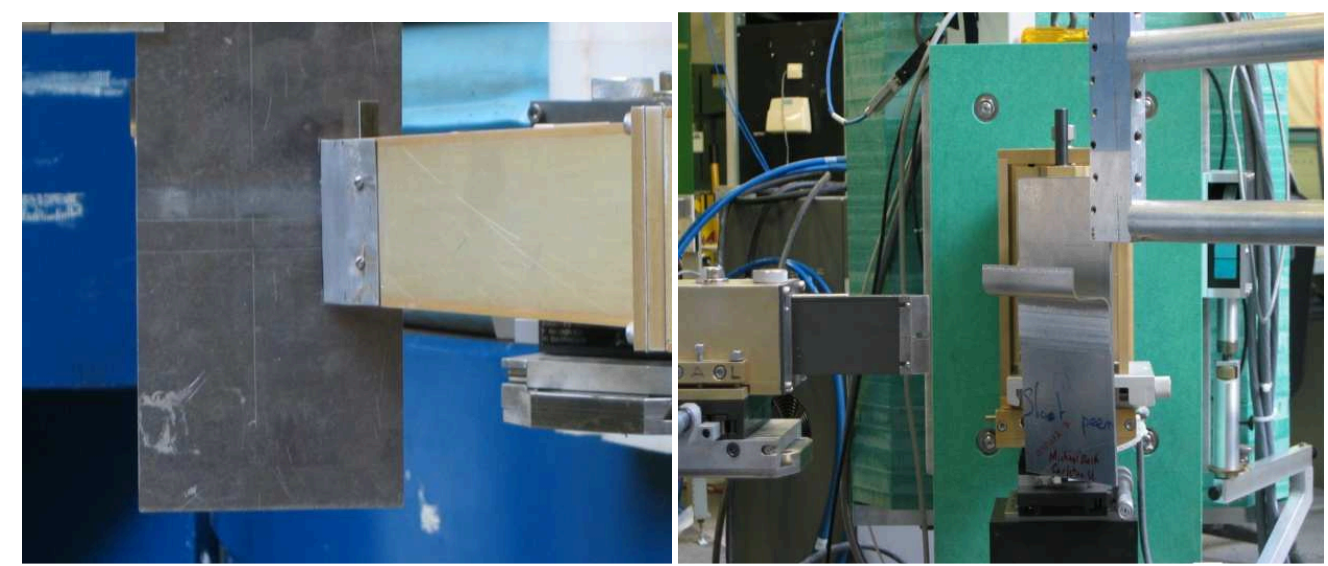

Figure 2: Close up view of test specimen setup with detector

\section{Results and Discussion}

\section{Transverse Residual Stress Component $\left(\sigma_{\mathrm{x}}\right)$}

The variation of the transverse residual stress component $\left(\sigma_{x}\right)$ in the transverse $(x)$ direction of both specimens is shown in Figure 3. The as-welded stresses are higher than the hammer peened specimen at every slit depth. The maximum tensile stress in the as-welded plate was $239 \mathrm{MPa}$ at a distance of $x=6 \mathrm{~mm}$ to right of weld centerline. This stress is $69 \%$ of the skins yield strength and $48 \%$ of the stringer's yield strength. In the hammer peened specimen, the maximum tensile residual stress was $122 \mathrm{MPa}$ at $\mathrm{x}=-8 \mathrm{~mm}$ to the left of the weld centerline. Comparing point by point across the weld in the transverse direction, the effects of hammer peening reduced the tensile residual stresses at every single point and in most cases caused the stress to change from tension to compression.

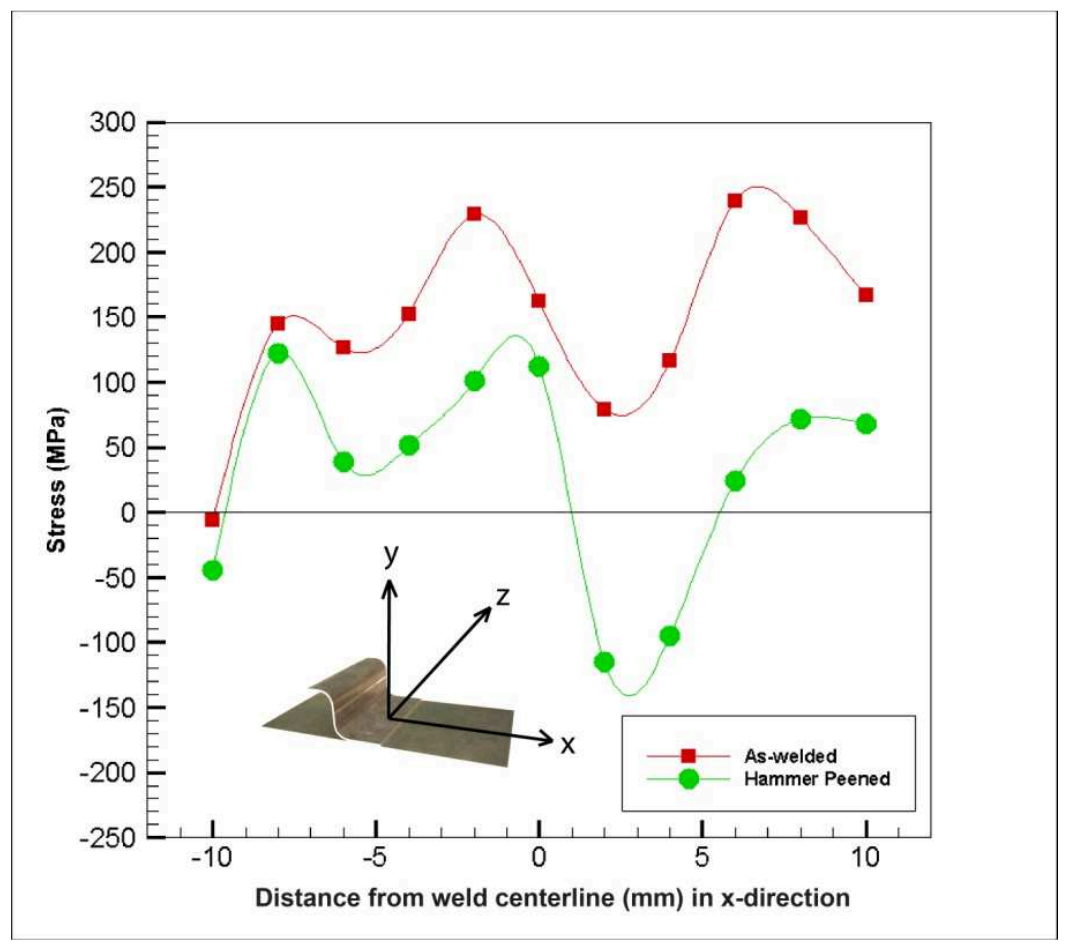

Figure 3: Transverse stress component $\left(\sigma_{\mathrm{x}}\right)$ in transverse $(\mathrm{x})$ direction

\section{Fatigue Life of Friction Stir Welded Specimens}

The results are from the load dependent fatigue testing of the two sets of test specimens. All samples with a dimension of 191 x $95 \times 3.76 \mathrm{~mm}$ were cyclically loaded between $32 \mathrm{KN}$ and $5 \mathrm{KN}$ 
at $10 \mathrm{~Hz}$ and a stress ratio of $\mathrm{R}=0.16$. For the given cross sectional area of the FSW lap joint, the maximum applied stress on the plate is $152.4 \mathrm{MPa}$. Figure 9 is the plot of the two set of fatigue tests compared with fatigue test of continuous (DP_C) and discontinuous (DP) double pass FSW lap joints by Jung [3]. Since Jung's maximum stress was $137.9 \mathrm{MPa}$ and the stress for this fatigue experiment was 152.4 MPa. Extrapolation of the graph (dotted line) show that if the stress on Jung's continuous double pass lap joint was increased from 137.9 MPa to $152.4 \mathrm{MPa}$, the sample would fail at approximately the same number of cycles as the as-welded specimens in these fatigue experiments did. The first as-welded test piece (AW1) failed after 86,000 cycles and the second aswelded plate (AW2) lasted 10,000 cycles more and failed at 96,000 cycles.

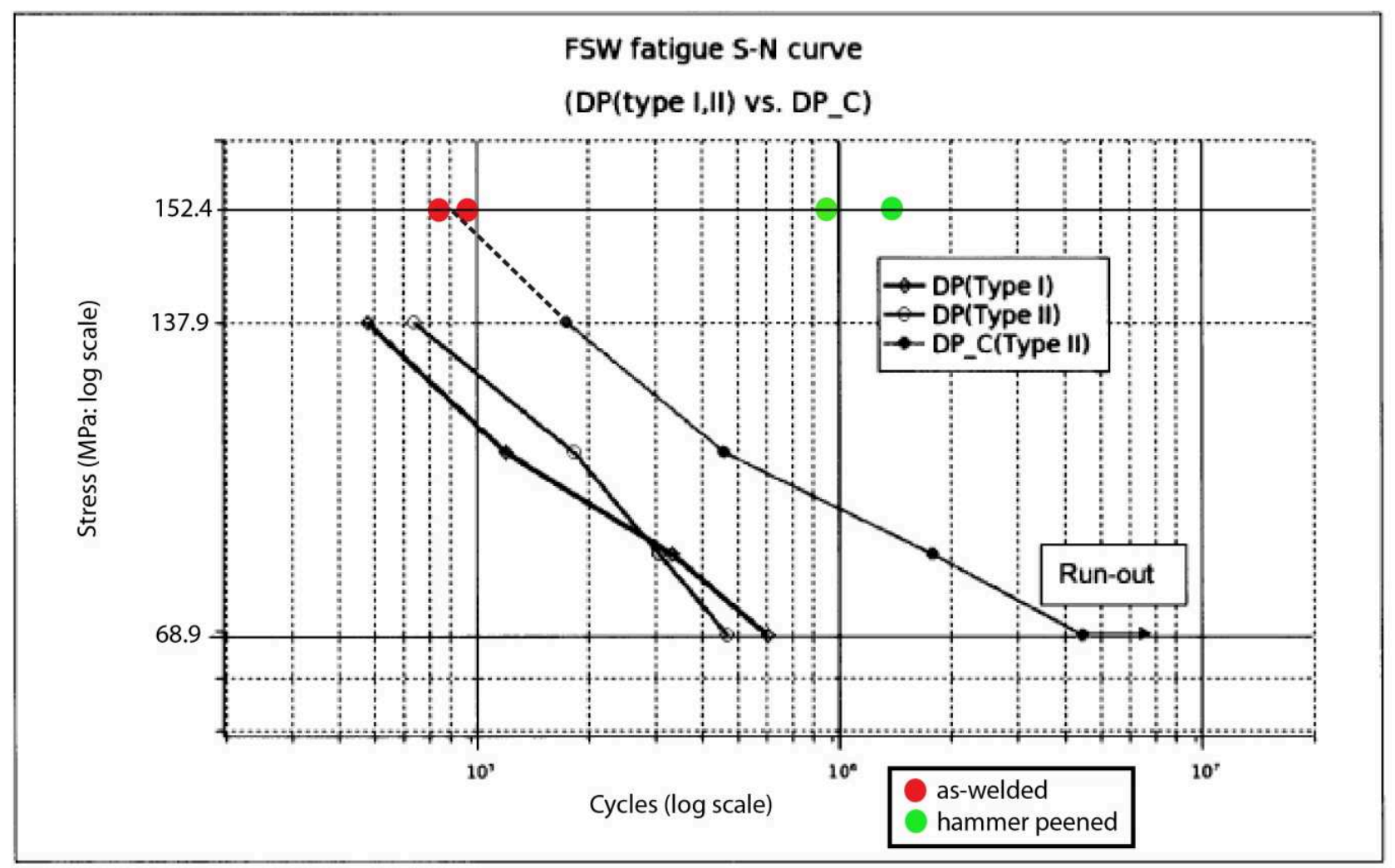

Figure 4: Cycles to failure of as-welded and hammer peened test specimens compared with previous fatigue testing of FSW lap joints, [3]

Identical loading parameters were used on the fatigue tests of the hammer peened plates, which failed after a much longer period of cycles than the as-welded specimens. Figure 4 plots the results of the hammer peened specimen with the as-welded specimens to show the effects of peening the weld on fatigue life. At a maximum stress level of $152.4 \mathrm{MPa}$, the first hammer peened specimen (HP1) failed after 1,100,000 cycles. This specimen did not fail near the weld centerline but instead failed right at the edge of the hydraulic grips contact with the plate. The crack appeared to have started from the edge and grew through the thickness of the plate, causing failure and complete separation. It is important to note that fretting (rubbing or chafing fatigue) was a possible failure mechanism as opposed to cyclic fatigue in this test specimen, which is common in aluminum alloys.

\section{Examination of Failure Location in the FSW Stringer-to-skin Lap Joints}

One of the primary goals of measuring these residual stresses is to have a better understanding of how these residual stresses affect the performance of these aerospace structures. This entails studying the causes of failure of the stringer-to-skin lap joint under service conditions due to the residual stresses present. Therefore, this section will combine all the quantitative measurements listed above to explain how the internal residual stresses in these FSW lap joints effects their 
performance and more importantly where the failure will occur which very few literatures have attempted to do.

In the as-welded test specimen, two peak transverse residual stresses $\left(\sigma_{\mathrm{x}}\right)$ were located on either side of the weld centerline in the region roughly between the weld nugget and the thermalmechanical affected zone (TMAZ). The highest value of transverse residual stress $\left(\sigma_{\mathrm{x}}\right)$ found at $\mathrm{x}=$ $6 \mathrm{~mm}$ to the right of the weld centerline. This tensile residual stress was 70\% of the AA 2024-T3's yield strength. The hardness value measured in the skin section at a distance of $\mathrm{x}=6 \mathrm{~mm}$ to the right of the weld centerline was $129 \mathrm{HV}$. This hardness value is low compared to the stringer and skins nominal hardness values of $175 \mathrm{HV}$ and $137 \mathrm{HV}$ respectively. The interface between the weld nugget and the TMAZ corresponds to low hardness regions because the original structure in this region is over aged and there is not enough solute left in the material. This area of the weld will be relatively ineffective in inhibiting dislocation motion and the strain localization in the softened area of the weld will result in degradation in the mechanical properties [4]. The low hardness value and high tensile residual stress coupled with the cyclic loading of $86 \mathrm{MPa}$ caused the residual stress in this region to the left of the weld centerline to be greater than the yield strength of the skin section causing crack to nucleate and eventual separation of the lap joint in the skin panel, $6 \mathrm{~mm}$ to the right of the weld centerline as shown in Figure 5.

On the left hand side of the weld centerline at a distance of $\mathrm{x}=-2 \mathrm{~mm}$, there was a second peak tensile stress measured at $224 \mathrm{MPa}$, which is $65 \%$ of the AA 2024-T3's yield strength. The hardness value measured at this location was $118 \mathrm{HV}$. Again, the combination of the high tensile stress and low hardness value caused the plate to fail $2 \mathrm{~mm}$ to the left of the weld centerline in the skin section.

The main conclusions taken from the examination of failure locations of the FSW lap joints before and after hammer peening is that there is detectable variations in residual stresses present in the friction stir welded lap joint. These calculated residual stresses are a consequence of avoiding distortion, which is due to the hindrance of shrinkage during the cooling of the weld. The effects of hammer peening reduced the residual stresses in all three principal directions of the plate. The experiments show that these residual stresses are altered after hammer peening and that the magnitude of the stresses was in most cases either reduced in tension of changed to compressive stresses.

When talking about fatigue performance of these FSW lap joints, the effect of residual stresses help rise (tensile stresses) or lower (compressive stresses) the mean stress or load ratio, $\mathrm{R}$, of the applied loading but the location of crack nucleation is still unclear. During the fatigue testing, it was observed that hammer peening the plates reduced the tensile residual stresses in the lap joints and increased the fatigue life by a factor of 10 . Due to the limited number of fatigue samples available, there is insufficient evidence to prove where the samples failed due to cracks caused by residual stress, geometrical notches at the weld toe, root defects or inclusions, therefore further testing is required. 


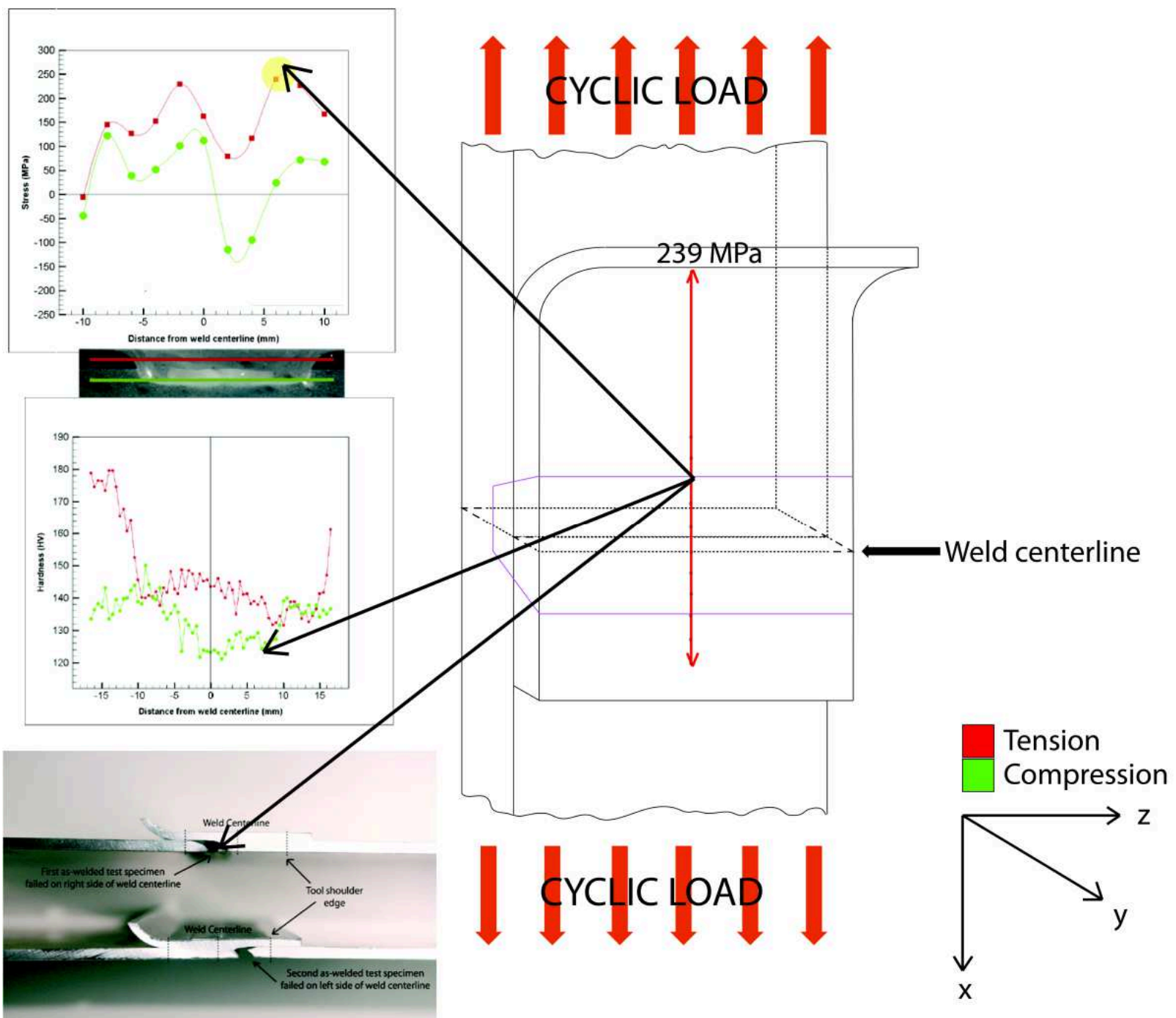

Figure 5: Failure of first as-welded sample possibly due to combination of high tensile residual stress and low hardness value to the right of weld centerline $(x=6 \mathrm{~mm})$ in region between weld nugget and TMAZ

Having said that, the knowledge of the residual stresses produced from the FSW process can be used by aircraft designers as a guide when designing aircraft components such as these stringer-toskin lap joints based on the damage tolerance approach. The designer has two choices; they can keep the residual stresses which are present in the as-welded configuration and design the aircraft to be serviced within the time period which is safe for that level of residual stress, or they can alter the residual stresses so that the fatigue life is improved and the aircraft is able to be in service for a longer period of time. The decision will be based on how much improvement on the lives of the component is achieved by the post welding process and how much money will that cost the manufacturers. Maintenance workers would be interested in the failure locations of these lap joints because it will allow them to focus on the weld region where failure is most likely to occur when detecting cracks and other defects in the lap joints.

\section{Acknowledgements}

The authors would like to thank Simon Larose and the team at the Ottawa and Montreal NRC campuses for the FSW operations and for providing the welds used in this experiment. The authors would also like to thank Michael B. Prime for his invaluable insight on the crack compliance 
method. This work was funded partially by Carleton University and the Institute for Aerospace Research at the National Research Council Canada.

\section{References}

[1] M. Ericsson, L.Z. Jin, R. Sandtrom, Fatigue properties of friction stir overlap welds, International Journal of Fatigue 68 (2005) 456-468.

[2] A. Merati, M. Gallant, Friction stir lap welding of AA7075-T6 stringers on AA2024-T3 skin, 2009.

[3] M. Jung, The Fatigue Characteristics of Friction Stir Welded Stiffened Panel Structure, Masters Thesis, 2007.

[4] O. Hatamleh, The Effects of Laser Peening and Shot Peening on Mechanical Properties in Friction Stir Welded 7075-T7351 Aluminum, ASM International 17 (2007) 688-694.

[5] P. Staron, M. Kocak, S. Williams, Residual stresses in friction stir welded Al sheets, Applied Physics A Materials Science \& Processing 74 (2002) 1161-1165.

[6] C.D. Dalle, Effect of Weld Imperfections and Residual Stresses on the Fatigue Crack Propagation in Friction Stir Welded Joints, Second International Conference on Friction Stir Welding Proceedings (2000) 2-10. 